\title{
Septic arthritis of the shoulder due to Ureaplasma urealyticum after emergency caesarean section: a case report
}

\author{
Jaad Mahlouly ${ }^{*^{*}} \mathbb{D}$, Loic Lhopitallier ${ }^{2} \mathbb{D}$, Véronique Suttels ${ }^{2} \mathbb{B}$, Linda Mueller ${ }^{3} \mathbb{D}$, Diane Wernly ${ }^{1} \mathbb{D}$, \\ Olivier Borens ${ }^{1}$ (D) and Sylvain Steinmetz ${ }^{1}$ (D)
}

\begin{abstract}
Background: Ureaplasma urealyticum is an intra-cellular bacterium frequently found colonizing the genital tract. Known complications include localized infections, which can result in premature deliveries. Septic arthritis due to $U$. urealyticum in healthy patients is exceptionally rare, although opportunistic septic arthritis in agammaglobulinemic patients have been reported. However, there are no reports of septic arthritis due to U. urealyticum following caesarean section or in the post-partum period.

Case presentation: A 38-year-old immunocompetent woman presented with severe right shoulder pain, 1 month following emergency caesarean section at 26 weeks of gestation for pre-eclampsia and spontaneous placental disruption with an uncomplicated post-operative recovery.

Our suspicion of septic arthritis was confirmed with abundant pus following arthrotomy by a delto-pectoral approach. Awaiting culture results, empirical antibiotic treatment with intravenous amoxicilline and clavulanic acid was initiated. In spite of sterile cultures, clinical evolution was unfavorable with persistent pain, inflammation and purulent drainage, requiring two additional surgical débridement and lavage procedures.

The 165 ribosomal RNA PCR of the purulent liquid was positive for $U$. urealyticum at $2.95 \times 10^{6}$ copies $/ \mathrm{ml}$, specific cultures inoculated a posteriori were positive for U. urealyticum. Levofloxacin and azithromycine antibiotherapy was initiated. Susceptibility testing showed an intermediate sensibility to ciprofloxacin and clarithromycin. The strain was susceptible to doxycycline. Following cessation of breastfeeding, we started antibiotic treatment with doxycycline for 4 weeks. The subsequent course was favorable with an excellent functional and biological outcome.
\end{abstract}

Conclusions: We report the first case of septic arthritis due to $U$. urealyticum after caesarean section. We hypothesize that the breach of the genital mucosal barrier during the caesarean section led to hematogenous spread resulting in purulent septic arthritis. The initial beta-lactam based antibiotic treatment, initiated for a purulent arthritis, did not provide coverage for cell wall deficient organisms. Detection of $16 \mathrm{~S}$ rRNA allowed for a correct microbiological diagnosis in a patient with an unexpected clinical course.

Keywords: Ureaplasma urealyticum, Septic arthritis, Caesarean section, Post-partum infection, Case report

\footnotetext{
*Correspondence: jaad.mahlouly@gmail.com

'Department of Orthopaedics and Traumatology, Lausanne University

Hospital (CHUV), Rue du Bugnon 46, 1011 Lausanne, Switzerland

Full list of author information is available at the end of the article
}

(c) The Author(s). 2020 Open Access This article is licensed under a Creative Commons Attribution 4.0 International License, which permits use, sharing, adaptation, distribution and reproduction in any medium or format, as long as you give appropriate credit to the original author(s) and the source, provide a link to the Creative Commons licence, and indicate if changes were made. The images or other third party material in this article are included in the article's Creative Commons licence, unless indicated otherwise in a credit line to the material. If material is not included in the article's Creative Commons licence and your intended use is not permitted by statutory regulation or exceeds the permitted use, you will need to obtain permission directly from the copyright holder. To view a copy of this licence, visit http://creativecommons.org/licenses/by/4.0/ The Creative Commons Public Domain Dedication waiver (http://creativecommons.org/publicdomain/zero/1.0/) applies to the data made available in this article, unless otherwise stated in a credit line to the data. 


\section{Background}

Ureaplasma urealyticum, a short intra- and extracellular rod lacking a cell wall, frequently colonizes the genital human tract. In the genital tract of sexually active healthy women, prevalence estimates range from 38 to $75 \%[1,2]$. This germ belongs to the genital mycoplasmas, containing Ureaplasma spp. and Mycoplasma spp., seven of which are referenced in humans on mucous membranes: $U$. urealyticum, $U$. parvum, $M$. pneumonia, $M$. ferentans, $M$. penetrans, $M$. genitalium and $M$. hominis $[1,3]$. They colonize mucosal surfaces and are mostly non-pathogenic, except for M. pneumoniae, which causes respiratory tract infections [1]. However, they all have the potential to invade tissues and cause opportunistic infections. To date, their exact pathogenicity remains to be determined.

The genus Ureaplasma is divided into two commensal species, $U$. urealyticum and $U$. parvum. $U$. urealyticum has been more frequently implicated in opportunistic infections in antibody deficient patients [3]. In the absence of antibodies, neutrophils phagocyte these bacteria, however they remain viable and are likely to proliferate [4].

Genital tract infection and premature birth have been associated to infection with $U$. urealyticum [5].. Some twenty cases of patients with septic arthritis due to $U$. urealyticum have been described in the literature and in all but two cases antibody deficiencies were identified [6-8].

Bone and joint infections can occur in the postpartum period, such as sacroiliitis by contiguous spread. Septic arthritis of a limb is rarer, and half a dozen described cases have revealed germs such as $S$. aureus, $M$. hominis or $S$. agalactiae [9-11].. However, there are no reports of septic arthritis due to $U$. urealyticum after caesarean section in the postpartum period in an immunocompetent patient.

\section{Case presentation}

In December 2019, a right-handed 38-year-old woman presented to the emergency department with increasing right shoulder pain and raised inflammatory parameters. Her past medical history was remarkable for paraplegia due to poliomyelitis in childhood and a residual epilepsy due to the sequelae of a subarachnoid hemorrhage. Apart from these conditions, for which she was wheelchairbound, this patient was in good general health with a previous non-pathologic and well-functioning right shoulder.

One month prior to her admission with shoulder pain, she was involved in a car accident as a result of a tonicclonic seizure. Upon admission, she developed hypertension with associated proteinuria and was diagnosed with a 26-week gestation previously unknown pregnancy and pre-eclampsia. She was previously nulliparous. At day six of hospitalization, the patient presented a spontaneous placental abruption and underwent an emergency caesarean section with a simple post-operative evolution.
Physical exam of her right upper extremity revealed a swollen, warm and painful right shoulder on palpation and mobilization without neurovascular disorder. On general examination, she had moderate asthenia without disorientation. The vital signs were: Temperature of $37.2^{\circ} \mathrm{C}$, heart rate at 104 beats per minute, blood pressure of $148 / 95 \mathrm{mmHg}$, respiratory rate at 23 per minute and an oxygen saturation within the norm (SpO2 95\% breathing ambient air).

Hemoglobin was $101 \mathrm{G} / \mathrm{L}$, leukocytes $9.8 \mathrm{G} / \mathrm{L}$, thrombocytes $305 \mathrm{G} / \mathrm{L}$ and C-reactive protein was increased to $271 \mathrm{mg} / \mathrm{L}$. Blood cultures were sent for culture.

Suspecting right shoulder septic arthritis without any degenerative sign on X-ray (Fig. 1), she underwent open surgical debridement, synovectomy and $9 \mathrm{~L}$ saline solution lavage of the right shoulder by a delto-pectoral approach with subscapularis tenotomy. Abundant pus at arthrotomy was observed with the observation of a stage 3 equivalent according to Gächter's classification [12].

Awaiting culture results, empirical antibiotic treatment with intravenous 2,2 $\mathrm{g} 3 \mathrm{td}$ amoxicilline and clavulanic acid was initiated.

Whilst the blood cultures and intra-operative cultures remained sterile (Fig. 2) without any crystals positivity on microscopic analysis, the clinical evolution was unfavorable with persistent pain, inflammation and purulent drainage. The patient required two additional surgical debridements and lavages on days 4 and day 7 after the first surgery. Both surgical interventions revealed persistent amounts of

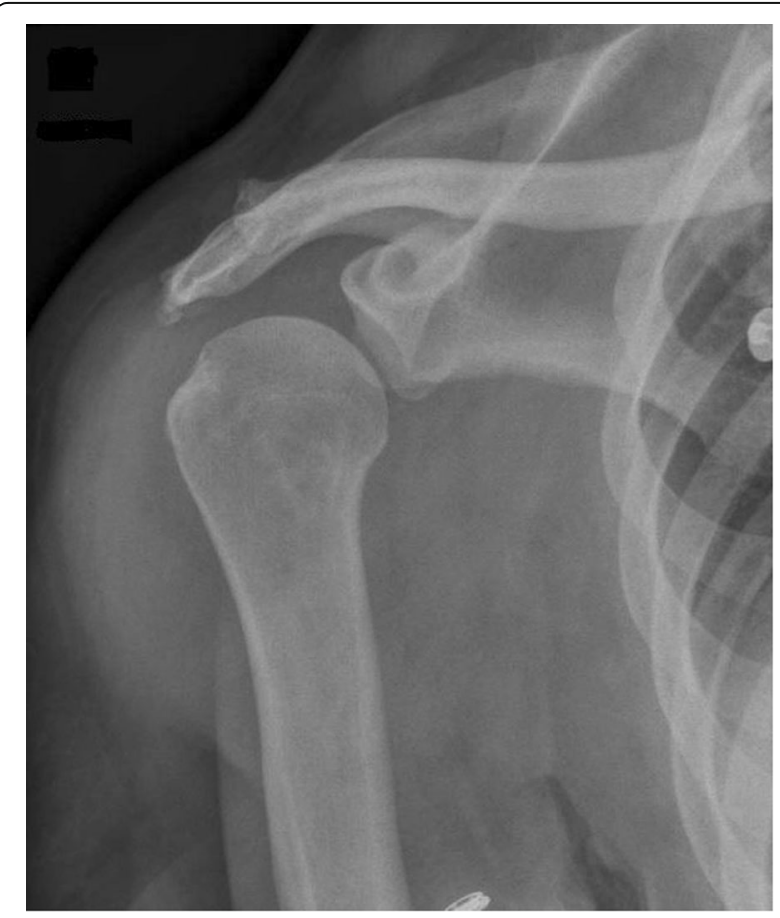

Fig. 1 Pre-operative AP right shoulder Xray without degenerative signs 


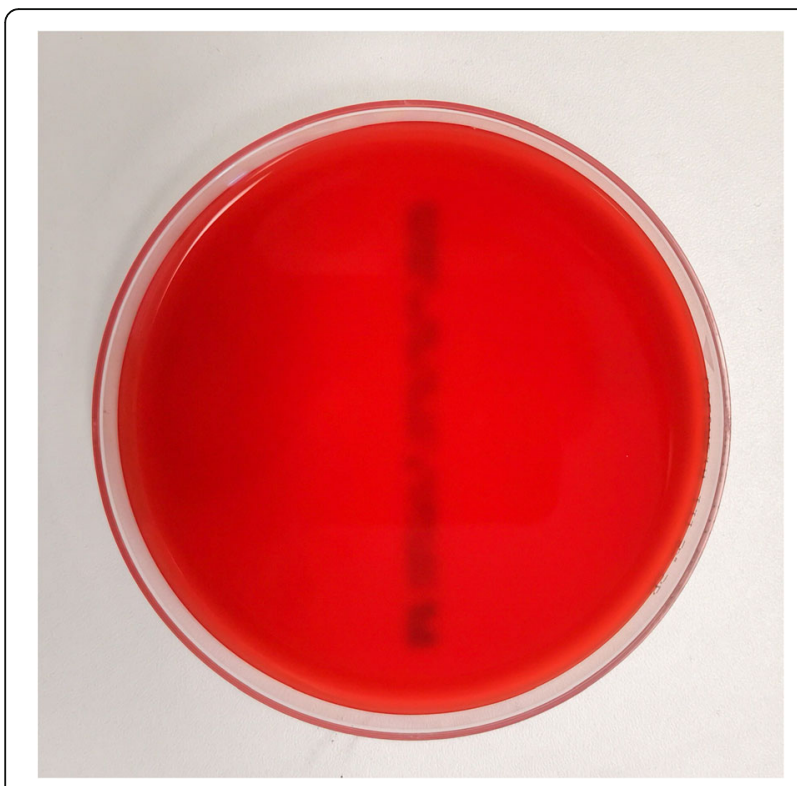

Fig. 2 Classic blood agar with absence of U. urealyticum growth

purulent and fibrous material despite the previous procedures and the empirical antibiotic treatment.

The 16S ribosomal RNA PCR performed on the purulent intra-operative liquid revealed $U$. urealyticum at $2.95 \times 10^{6}$ copies $/ \mathrm{ml}$ (Fig. 3), positive specific cultures inoculated a posteriori confirmed this finding (Fig. 4).

Cervical smear showed no simultaneous $U$. urealyticum genital infection. Fresh placental tissue was not available for further testing, but there was no evident macroscopic chorio-amnionitis.

Upon receiving the microbiological documentation, a bi-therapy of levofloxacin and azithromycine was initiated. Susceptibility testing showed an intermediate sensibility to

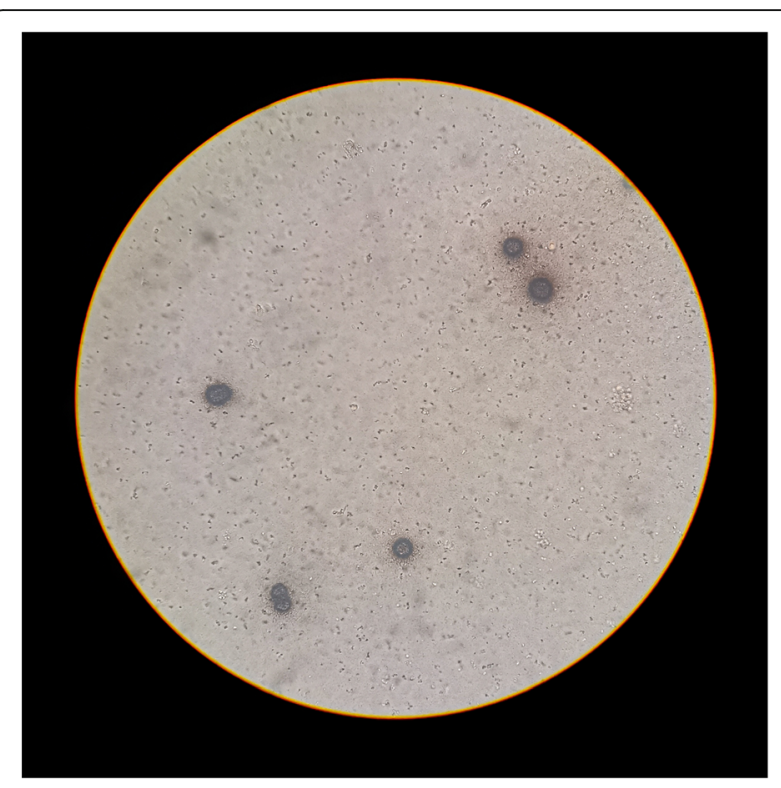

Fig. 4 Microscopic view of characteristic $U$. urealyticum colonies on rich media supplemented with yeast extract and urea (10x)

ciprofloxacin and clarithromycin. The strain was susceptible to doxycycline. Following cessation of breastfeeding, we started treatment with doxycycline for 4 weeks according to the guidelines of our institution and on the basis of the low initial therapeutic response [13]. Early mobilization was started with our physiotherapist (Fig. 5). She showed a favorable course with an excellent biological and functional outcome with a post-surgical DASH score of 5,8 at 3 months follow-up [14]. As a reminder, a DASH score of 0 represents no disability and a score of 100 represents severe disability after surgery. Concerning the father of the infant, no other specific considerations were

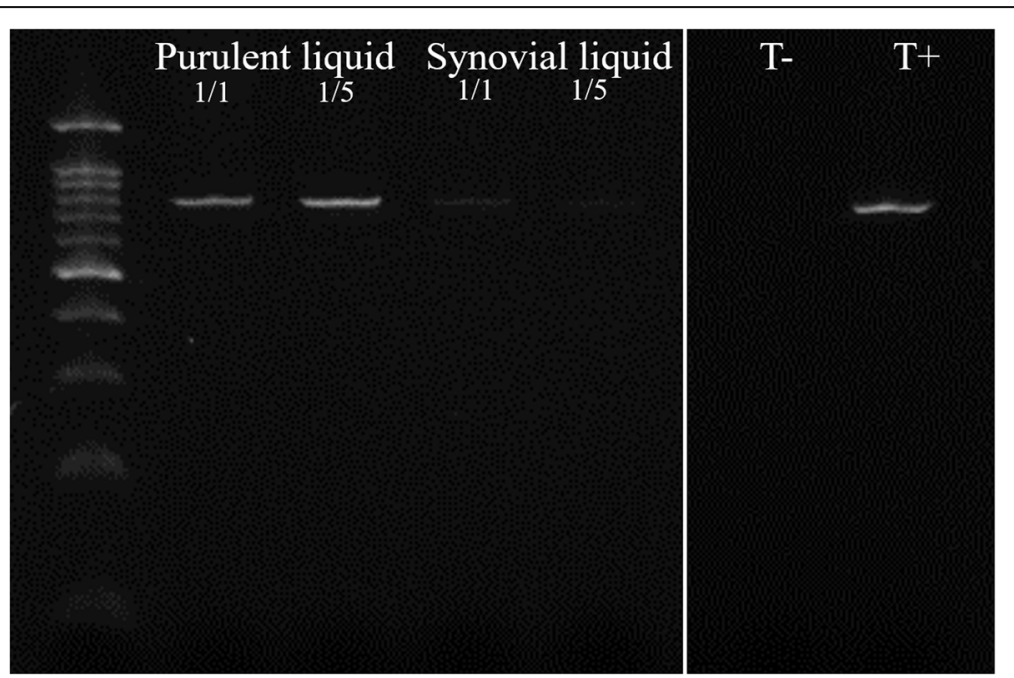

Fig. 3 PCR amplification identifiing U. urealyticum (Purulent liquid and Synovial liquid 1/1 and 1/5 are different dilutions of samples. T- and T+ are negative and positive controls) 


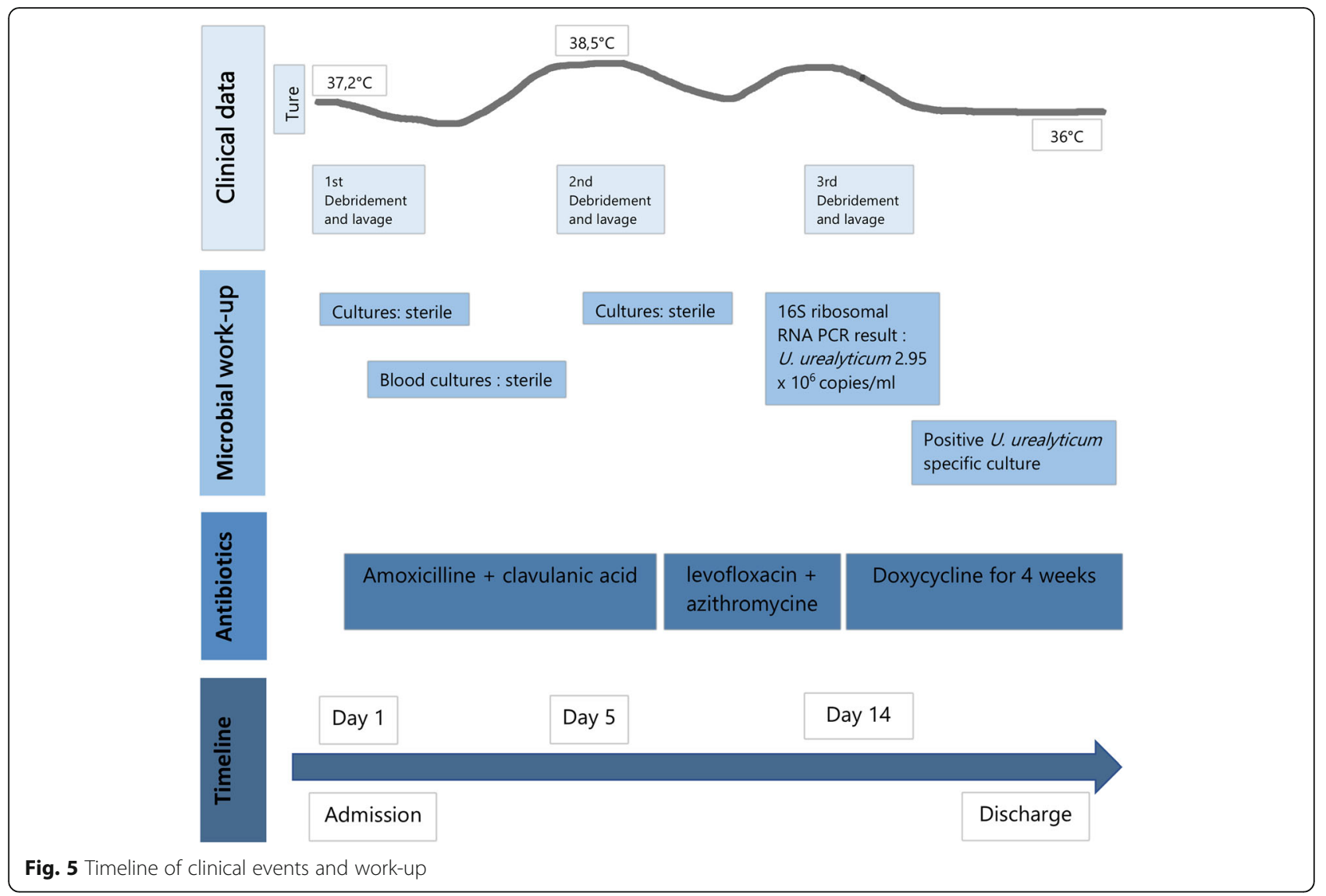

taken related to this infection. The infant presented good clinical evolution.

\section{Discussion and conclusions}

Arthralgias during pregnancy and in the postpartum period are common, moreover our patient did not present with fever on admission [15]. These common arthralgias may be due to hormonal changes and changes in joint ligament laxity, a condition more common in the lower limbs [9]. It is therefore important to perform a laboratory work-up to differentiate these arthralgias from inflammatory or infectious pathology.

$U$. urealyticum is frequently found in the genital tract and normally elicits a response from the humoral immune system $[1,4]$. Deficits in this type of response are a risk factor for septic arthritis [8]. In the absence of antibodies, these organisms are phagocytized by neutrophils but are not degraded and remain viable and able to proliferate [4]. To date and to our knowledge, only two cases of $U$. urealyticum septic arthritis have been reported in healthy patients, both with involvement of the knee $[6,7]$.

Concerning septic arthritis in the postpartum period, there are to our knowledge only eight cases described in the limb joints: wrist, hip, knee and only one shoulder. They all involve germs who were located in the genital tract (S. aureus, $M$. hominis or group B streptococci) and some of them have occurred after caesarean section procedures [9-11]. Involvement of the sacroiliac joint or the pubis is more frequent and probably due to contamination by continuous spread [16].

We believe that the breach of the genital mucosal barrier during the caesarean section led to hematogenous spread inoculating the shoulder and causing purulent septic arthritis. Antibiotic prophylaxis prior to genital surgery is important and can reduce the incidence of perioperative infections, but it cannot eradicate them, especially since it does not cover all the different types of pathogens [17, 18]. The atypical presentation at 3 weeks post-surgery could be explained by the post-partum maternal immune boost, with increased innate and specific immune deficiencies, revealing a previously clinically silent infection [19].

Septic arthritis of native shoulder can have serious local consequences such as rapid joint degeneration or loss of function or cause systemic implication such as septic shock $[9,20]$. Half of the patients with acute septic arthritis of native shoulder do not regain their previous level of activity after such a condition [21]. Treating the causative agent radically with surgery in conjunction with targeted adjuvant antibiotic therapy is essential to preserve function of the shoulder and reduces systemic complications [22]. 
All the more so in a patient who is paraplegic and righthanded.

Mycoplasma spp. and Ureaplasma spp. should be included in the microbiological differential diagnosis of the etiology of culture sterile purulent arthritis in the postpartum period.

Beta-lactam antibiotic treatment, initiated empirically for a purulent arthritis, does not provide coverage for cell wall deficient organisms. Failure of beta-lactam antibiotics in purulent arthritis raises a suspicion of resistant or atypical causal pathogens such as mycobacteria, fungi or Mycoplasma spp. Indeed, beta-lactams have no effect on Mycoplasma spp. lacking precisely the cell-wall targeted by these antibiotics. When confronting purulent arthritis with repeated sterile cultures, bacterial identification using PCR detection of $16 \mathrm{~S}$ ribosomal RNA can sometimes allow for a correct microbiological diagnosis given its suboptimal sensitivity of about $58 \%$ and specificity of $85 \%$. A positive test result can be validated a posteriori using specific PCR probes and culture media [23, 24].

In conclusion, we described the first case of septic arthritis due to $U$. urealyticum after genital surgery or in the post-partum period. We note all the more the fact that this is, to our knowledge, the third septic arthritis and specifically the first shoulder septic arthritis due to $U$. urealyticum in an immunocompetent host. We hypothesize that genital intervention led to hematogenic spread and resulting in purulent septic arthritis.

When facing an adverse clinical course of purulent arthritis in spite of multiple surgical débridements and sterile cultures in the post-partum period, we advise additional testing by $16 \mathrm{~S}$ rRNA PCR to look for atypical bacteria, such as $U$. urealyticum to improve the targeting of antimicrobial treatment.

\section{Abbreviations \\ DASH score: The disabilities of the arm, shoulder and hand (DASH) questionnaire; Mycoplasma spp.: Species of the genus Mycoplasma; PCR: Polymerase chain reaction; rRNA: Ribosomal ribonucleic acid; $U$. urealyticum: Ureaplasma urealyticum; Ureaplasma spp.: Species of the genus Ureaplasma}

\section{Acknowledgements}

Not applicable.

\section{Authors' contributions}

JM collected the patients' health related data. JM, LL, VS, LM, DW, OB and SS wrote and revised the manuscript. All authors have read and approved the final manuscript.

\section{Funding}

This study was funded by the Department of Orthopaedics and Traumatology, University of Lausanne.

\section{Availability of data and materials}

Whole medical history, vital signs and laboratory values are available in the patient computerized medical file of University Hospital of Lausanne, Switzerland
Ethics approval and consent to participate

Not applicable.

\section{Consent for publication}

The patient provided written informed consent for the use of her biological material and her health-related and microbiological data for this study. The patient provided written informed consent for the publication of the case study.

\section{Competing interests}

No competing financial interests exist for any of the authors.

\section{Author details}

1Department of Orthopaedics and Traumatology, Lausanne University Hospital (CHUV), Rue du Bugnon 46, 1011 Lausanne, Switzerland. ${ }^{2}$ Department of Infectious Diseases, Lausanne University Hospital (CHUV), Lausanne, Switzerland. Institute of Microbiology, University of Lausanne, Lausanne University Hospital (CHUV), Lausanne, Switzerland.

Received: 26 July 2020 Accepted: 8 October 2020

Published online: 17 October 2020

\section{References}

1. Kletzel HH, Rotem R, Barg M, et al. Ureaplasma urealyticum: the role as a pathogen in Women's health, a systematic review. Curr Infect Dis Rep. 2018; 20:33.

2. Baum SG. Mycoplasma infections. In: Goldman L, Schafer Al, editors. Goldman's Cecil medicine. 24th ed. Cambridge: Elsevier; 2012. p. 1912-6.

3. Ka B, Chung D, Cunningham-Rundles C. Osteoarticular infectious complications in patients with primary immunodeficiencies. Curr Opin Rheumatol. 2008;20(4):480-5.

4. Webster AD, Furr PM, Hughes-Jones NC, et al. Critical dependence on antibody for defense against mycoplasmas. Clin Exp Immunol. 1988;71(3):383-7.

5. Potts JM, Ward AM, Rackley RR. Association of chronic urinary symptoms in women and Ureaplasma urealyticum. Urol. 2000;55:486-9.

6. Vittecog $\mathrm{O}$, Schaeverbeke $\mathrm{T}$, Favre $\mathrm{S}$, et al. Molecular diagnosis of Ureaplasma urealyticum in an immunocompetent patient with destructive reactive polyarthritis. Arthritis Rheum. 1997:40(11):2084-9.

7. Sethi S, Sharma M, Gill SS. Septic arthritis due to Ureaplasma urealyticum. Indian Pediatr. 2000;37:552-4.

8. Furr PM, Taylor-Robinson D, Webster AD. Mycoplasmas and ureaplasmas in patients with hypogammaglobulinaemia and their role in arthritis: microbiological observations over twenty years. Ann Rheum Dis. 1994;53(3):183-7.

9. Patel $\mathrm{S}$, Trehan R, Kinmont C. Post-partum septic arthritis of the knee : a case report Cases J. 2009:2.7132

10. Phuah $\mathrm{CL}$, Javid B, Aliyu SH, et al. A case of mycoplasma hominis septic arthritis postpartum. J Inf Secur. 2007:55:e135-7.

11. Imam YZ, Aldeen Sarakbi H, Abdelwahab N, et al. Streptococcus agalactiae septic arthritis of the shoulder and sacroiliac joints : a case report. Case Rep Rheumatol. 2012;2012:720297.

12. Der GA. Gelenkinfekt Inform Arzt, vol. 6; 1985. p. 35-43.

13. Zimmerli W, Borens $\mathrm{O}$. Infectious arthritis. In: Ochsner P, Borens O, Bodler PM, et al., editors. Infections of the musculoskeletal system. Grandvaux: Swiss Orthopaedics; 2016. p. 147-55.

14. Gummesson C, Atroshi I, Ekdahl C. The disabilities of the arm, shoulder and hand (DASH) outcome questionnaire: Iongitudinal construct validity and measuring self-rated health change after surgery. BMC Musculoskelet Disord. 2003:4:11.

15. Vullo VJ, Richardson JK, Hurvitz EA. Hip, knee, and foot pain during pregnancy and the postpartum period. J Fam Pract. 1996:43(1):63-8.

16. Ducrotoy $V$, Fournet $P$, Vittecoq $O$, et al. Postpartum septic arthritis. Two case reports. J Gynecol Obstet Biol Reprod (Paris). 1998;27(4):449-54.

17. Sway A, Wanyoro A, Nthumba P. Prospective cohort study on timing of antimicrobial prophylaxis for post-cesarean surgical site infections. Surg Infect. 2020;21(6):552-7.

18. Rickard J, Beilman G. A global strategy for the management of surgical infections. Surg Infect. 2020:21(6):477.

19. Groer MW, Davis MW, Smith K, et al. Immunity, inflammation and infection in post-partum breast and formula feeders. Am J Reprod Immunol. 2005;54: 222-31. 
20. Klein RS. Joint infection, with consideration of underlying disease and sources of bacteremia in hematogenous infection. Clin Geriatr Med. 1988;4:375-94.

21. Gramlich Y, Klug A, Walter G, et al. Septic arthritis of native shoulder and knee joint : what are the differences in bacterial spectrum, treatment, and outcome? Surg Infect. 2019;21(4):391-7.

22. Perry CR. Septic arthritis. Am J Orthop. 1999;28:168-78.

23. Cunningham SA, Mandrekar JN, Rosenblatt JE, et al. Rapid PCR of mycoplasma hominis, Ureaplasma urealyticum and Ureaplasma parvum. Int J Bacteriol. 2013; 2013:168742.

24. Akram A, Maley M, Nguyen T, et al. Utility of $16 \mathrm{~S} r$ RNA PCR performed on clinical specimens in patient management. Int J Infect Dis. 2017;57:144-9.

\section{Publisher's Note}

Springer Nature remains neutral with regard to jurisdictional claims in published maps and institutional affiliations.

Ready to submit your research? Choose BMC and benefit from:

- fast, convenient online submission

- thorough peer review by experienced researchers in your field

- rapid publication on acceptance

- support for research data, including large and complex data types

- gold Open Access which fosters wider collaboration and increased citations

- maximum visibility for your research: over $100 \mathrm{M}$ website views per year

At $B M C$, research is always in progress.

Learn more biomedcentral.com/submissions 